\title{
A Partnership-Designed Online Module on Climate Science: Impact on Year 10 Teachers and Students
}

\author{
Wan $\mathrm{Ng}^{1 *}$ \\ ${ }^{1}$ School of Education, University of Technology Sydney, New South Wales, AUSTRALIA
}

Received 25 March 2018 - Revised 3 September 2018 - Accepted 26 October 2018

\begin{abstract}
Climate change is a layered, complex phenomenon and is contested in the public arena. For students to understand it and its likely consequences, they need to be well educated in climate science literacy i.e. be able to analyse and relate multiple sources of data and engage in arguments that are presented in the media. This paper aimed to investigate the design and impact of a school-university-industry designed online module on climate science on Year 10 teachers and their students' experiences in climate science literacy development. Created with 'next generation' software, the emodule allowed for personalised learning on an adaptive platform. Using a mixedmethod approach, quantitative data was gathered through post-project questionnaires while qualitative data was obtained from focus group interviews, observations and open-ended questions in the survey. The findings indicate that a three-way partnership drawing on the partnership's respective expertise created learning resources that were accurate and beneficial for both students and teachers. The findings showed that teachers and students were generally positive about their experiences but more scaffolding would have benefited students and that successful teachers were those who invested time to explore and internalise the content of the e-module.
\end{abstract}

Keywords: adaptive and personalised learning, climate science literacy, impact of emodule, secondary school students and teachers

\section{INTRODUCTION}

Climate science, the science of climate change has been the subject of debate as well as confusion in the past few decades (e.g. Johnson, 2016; McCaffrey \& Buhr, 2008; Oreskes, 2004; Pruneau, Khattabi \& Demers, 2010). Climate scientists have alerted the general public of the dangerous effects of global warming due to the effect of greenhouse gases emitted into the earth's atmosphere through various ways but mostly through human's actions. They have cautioned on the potential drastic effect of global warming on our ecosystem and subsequently on our economy and health. Others are more skeptical and think that the impact of global warming as well as the increase in average temperature to our planet is exaggerated. For students to be able to enter into such debates, it is important that they be well versed in climate science literacy and develop knowledge and understanding of the science of climate change. Climate science literacy will also enable them to make scientifically sensible and informed decisions about sustainability that may affect their lives as future citizens.

Climate science literacy is a component of environmental science literacy, both falling under the broad umbrella of scientific literacy. Similar to scientific literacy, climate science literate people are able to think critically and apply climate science knowledge to solve problems of the environment and its sustainability. The U.S. Global Change Research Program (2009) asserts that climate science literate individuals have an understanding of the essential principles of the earth's climate system, they are able to assess scientific information about climate from credible sources and are able to communicate meaningfully about climate and its changes as well as being able take responsible actions based on informed decisions. These capabilities also include the understanding that it is through observations, record keeping and computer modelling as well as the ability to assess the validity of scientific

(C) 2019 by the authors; licensee Modestum Ltd., UK. This article is an open access article distributed under the terms and conditions of the Creative Commons Attribution License (http://creativecommons.org/licenses/by/4.0/). \Wan.Ng@uts.edu.au (*Correspondence) 


\section{Contribution of this paper to the literature}

- A model of how partnerships between school-university-industry can work in designing, producing and implementing a technology-enhanced learning online module on climate science. The theoretical framework is discussed.

- An outline of the e-module and its features (e.g. feedback, simulations) hosted on a personalised and adaptive platform that contribute to students' learning. The analytics that inform teachers of students' progress is also outlined.

- The research evaluation on the impact of the school-university-industry partnership-designed e-module on students and teachers is presented.

- Implications of the research are discussed.

arguments based on evidence that scientific knowledge about climate change has been gathered (Dupigny-Giroux, 2010).

\section{CHALLENGES OF CLIMATE SCIENCE LITERACY EDUCATION}

Pruneau, Khattabi and Demers (2010) attribute challenges in climate change education as (i) cognitive (the conceptions people build up and the association with misconceptions), (ii) social and psychological (weak connection to nature and limited awareness about the realities of climate change and its impacts) and (iii) behavioral challenges (values and behavior that are unfavorable to the environment or self-perception of little authority to impact behavioral modification).

Educationally, Dupigny-Girous (2010) identified six challenges for climate science literacy: (i) the language of climate science (ii) the role of misconceptions (iii) where climate science lie in the curriculum (iv) the importance of learning styles in climate science education (v) educators can make a difference and (vi) the role of life experience. In an already crowded curriculum in the classroom, where does climate science literacy fit into it is often a dilemma for teachers. While educators can make a real difference to students' climate science literacy, the number of highly qualified K-12 earth science teachers or teachers adequately trained in climate science is insufficient and this has contributed to the lack of awareness and interest in geosciences curriculum amongst students (Dawson, 2012; Dupigny-Girous, 2010). Hence it is not unusual that students gain their knowledge of climate science from the media, magazines, the Internet and movies. Due to the continually evolving nature of climate science, the use of language and scientific information in these medium may be erroneously reported or misleading (Dawson \& Carson, 2013; Huertas \& Adler, 2012), resulting in misconceptions of climate science.

Misconceptions could be defined as inaccurate views of an issue, against a body of scientific knowledge and could be due to a lack of clarity or incorrect perception of the issue (Manolas \& Leal Filho, 2011). Misconceptions are an impediment to learning (Hewson, A'B \& Mariana, 1988) and climate science misconceptions are a barrier to actions against climate change at both the individual and societal level. Research studies on misconceptions that have involved both students and the general public have identified a number of common misconceptions such as: confusing weather and climate (Papadimitriou, 2004; Read et al., 1994); confusing ozone depletion with climate change i.e. ozone depletion contributing to increase in global temperature (Boyes \& Stanisstreet, 1998; Österlind, 2005; Papadimitriou, 2004) and identifying unrelated pollutants' effects such as photochemical smog, insecticides and nuclear waste to global climate change (Papadimitriou 2004; Read et al., 1994). In the intervention reported in this paper, common misconceptions such as these were addressed through the purposeful design of the content, simulation and quizzes by experts in the field - the climate science scientists.

\section{EDUCATIONAL STRATEGIES FOR CLIMATE SCIENCE LITERACY}

Heimlich and Ardoin (2008) asserted that in environmental education, transmitting knowledge alone will not persuade people to take action on the environment. It is necessary to develop capacities in students that entails knowledge, empowerment and desire to act on environmental issues. According to Pruneau, Khattabi and Demers (2010), in environmental education, the objectives of awareness, knowledge, state of mind, competences and participation (environmental action) should be observed. Pruneau et al's (2005) identification of pedagogical strategies in climate science literacy that achieve these objectives include education through pictures since visual aids can better explain the greenhouse effect to young people, for example a simple illustration of a layer of carbon dioxide or methane gas covering the earth and retaining heat. They also showed that experiential pedagogy in nature (observation activity in a location) was able to influence students to re-establish connections with the particular environment. This in turn encouraged them to develop the desire to protect local ecosystems from climate change. 


\section{Use of Digital Technology in Environment Education}

The use of digital technology is one of the ways to engage students in environmental education.

Hill and Nelson (2011) showed that the use of video podcasts was able to support students learning about ecosystems in a visual and flexible way. Students found the video podcasts to be effective in supporting learning and that the visual images and simulations were useful for revision. Leppisaari and Lee (2012) reported on an international collaborative virtual learning environmental education project between Korean and Finnish primary students. The researchers framed an operational model that illustrated the motivational affordances of technology such as the visualisation of knowledge, the display of student artifacts (e.g. local waste management photos) and the use of virtual spaces that enabled the communication between students from the two countries to take place. The use of digital games for environmental education has been reported by Yang, Chien and Liu (2012). Their study made use of a pet avatar to engage students to learn about home-energy conservation and to adopt appropriate energy conservation measures in the home. The result of the study showed that the digital game was able to promote the students' understanding of energy conservation, self-awareness and willingness to conserve energy. In their EcoMOBILE project, Kamarainen et al. (2013) reported on the use of a combination of augmented reality in mobile devices and probeware to study a local pond environment on a field trip. The augmented reality application was used to navigate the pond environment and to observe virtual media and information overlaid on the physical pond. Probeware was used to measure the quality of the pond water at designated augmented reality hotspots. The researchers found gains in the affective measures of students and deeper understanding of the content. $\mathrm{Ng}$, Parahakaran and Thien (2015) made use of blended learning tools (e.g. smart phones, tablets, webinar, skype) for students to learn about Disaster Risk Reducation for Sustainable Living. The results showed that students were positive about the use of blended learning tools to enhnce their awarenss and knowledge in environmental education.

There are, however, limited studies on the use of new technology in climate science education where interactive inquiry-based learning online modules are created on adaptive and personalised platform. This research investigated the use of a smart science module, called E $\Delta \mathrm{RTH}$, to develop the conceptual knowledge of climate science in Year 10 students as well as their capacities to apply evidence-based actions in creating a planet, in virtual space, that is safe and habitable for humans. Using 'next generation' software, the e-module allowed for personalised learning on an adaptive platform where embedded analytics could inform teachers on the progress of their students. E $\Delta$ RTH was part of a larger project called Smart Science Initiative that was funded by the Australian Government's Australian Science and Mathematics Partnership Program (Ng \& Fergusson, 2015). The project was a partnership project between universities, schools and the technology company Smart Sparrow. It brought together experts in pedagogy (secondary science teachers), content knowledge (university scientists) and software development (educational technology design experts from Smart Sparrow) to develop the climate change module. This research examined the input of each of these partners in the design and production of the smart science module E $\triangle$ RTH as well as its impact on teaching and Year 10 students' learning.

The broad research question was 'What impact does a partnership-designed e-module on climate science literacy have on secondary school students and teachers?' The sub-questions were:

1. As pedagogical experts, what were the Year 10 science teachers' expectations of and contribution to the design of the partnership e-module E $\Delta$ RTH?

2. What were the Year 10 students' and their teachers' perceptions of the impact of the E $\Delta \mathrm{RTH}$ e-module on their learning?

\section{THEORETICAL FRAMEWORK: TPACK PARTNERSHIP}

The theoretical framework underpinning this research is a school-university-industry TechnologicalPedagogical-and-Content Knowledge (TPACK) partnership framework previously reported by Ng and Fergusson (2017) and as shown in Figure 1. The framework embraces the three partners' expertise where scientists provided cutting-edge content knowledge, science teachers provided pedagogical knowledge of student learning and the technology partner represented these elements (content and pedagogy) in the form of digital learning materials for teaching and learning. Hence, collectively the three partners represented the three elements of technological pedagogical content knowledge (TPACK) for science. 


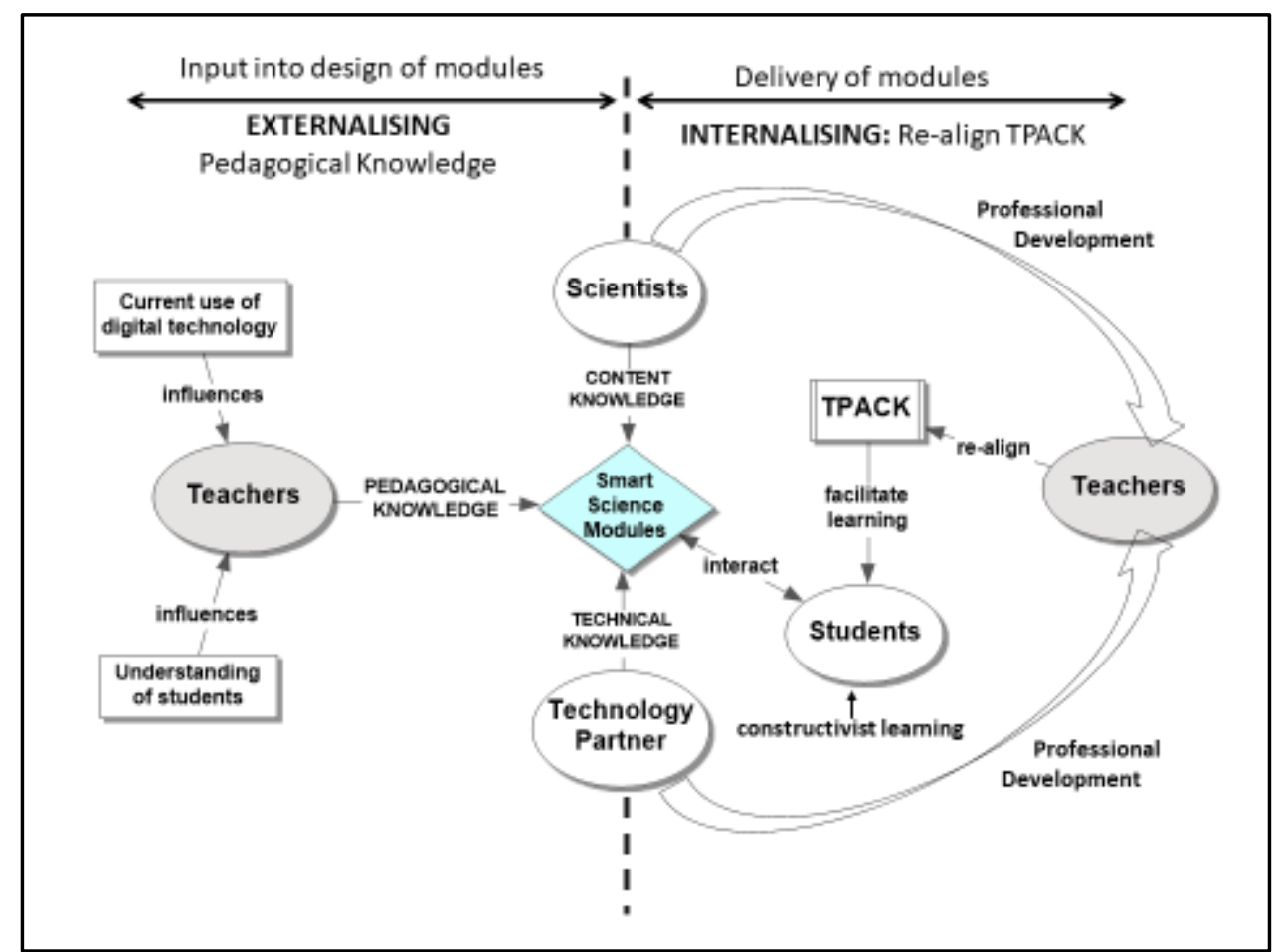

Figure 1. Theoretical framework for the design and delivery of E $\triangle \mathrm{RTH}$ e-modules (adapted from Ng \& Fergusson, 2017, p.6)

TPACK was first proposed by Mishra and Koehler (2006) as a model built on Shulman's (1987) representation of the knowledge needed to teach specific content, i.e. pedagogical content knowledge (PCK) model. In order to connect successfully between science (content), pedagogy, and technology, teachers will need a broad range of knowledge and skills that include the knowledge of science content, science curriculum, students' misconceptions, learning strategies supported by technology, the affordances of technology tools and teacher's skills to scaffold students' learning in a technology-enhanced environment (Jimoyiannis, 2010).

In the TPACK partnership framework illustrated in Figure 1, the two inputs of pedagogical knowledge by science teachers were at: (i) the design of the E $\triangle$ RTH module stage where the teachers externalise their pedagogical knowledge with respect to how students learn science that is supported by technology as well as (ii) the implementation and delivery of the e-module stage where the teachers assimilate and internalise the new knowledge and technology skills presented by the new module and re-align them with their existing TPACK to facilitate their students' learning in the classroom. This re-alignment of TPACK would require time for the teachers to familiarise themselves with the science content as well as the use of the new platform and its associated technologies. How much time the teachers will require will depend on their existing TPACK and attitudes towards adopting new technologies for learning.

In the framework, students' learning of the E $\Delta \mathrm{RTH}$ module is constructivist where they actively interact and engage with the learning materials to construct new knowledge and develop their climate science literacy.

\section{METHODOLOGY}

The research made use of a mixed-method approach, as reported by Ng and Fergusson (2017). Quantitative data was gathered through surveys while qualitative data to enhance the quantitative data was gathered via focus group interview, observation and open-ended questions in the survey. The robustness of the qualitative data, as discussed by Ng and Fergusson (2017), made use of the framework of Guba and Lincoln's (1994) criteria to evaluate what they termed 'trustworthiness' or rigour in qualitative research (Guba, 1981; Guba \& Lincoln, 1994; Lincoln \& Guba, 1985, 1986).The criteria of Guba and Lincoln (1994) as analogues to quantitative research terms are credibility, transferability, dependability and confirmability where credibility is an analog to internal validity; transferability is an analog to external validity; dependability is an analog to reliability; and confirmability an analog to objectivity. Lincoln and Guba (1986) suggested rigour may be achieved by qualitative researchers using such strategies as: prolonged engagement; persistent observation; thick, rich description; negative case analysis; peer review or debriefing; clarifying researcher bias; member checking; external audits and triangulation. The provisions made in this study to ensure the rigour of the research design followed Lincoln and Guba's (1986) trustworthiness criteria, as described in detail in $\mathrm{Ng}$ and Fergusson $(2017$, p. 8). 
To address the research sub-question 1, focus group interviews were conducted with Year 10 teachers participating in the project, prior to the designing and production stages of the e-module E $\Delta \mathrm{RTH}$. The focus groups enabled the gathering of qualitative data that provided insights into the opinions and experiences of the teachers, reflecting their attitudes, beliefs and views on effective technology-supported teaching and learning.

To address research question 2 that investigated the impact of the e-module on teachers' practice and students' learning experiences, post-project surveys were conducted with the participating students and teachers. The purpose of the post-project survey, completed by teachers after deployment of the modules, was to elicit their perceptions about the modules, whether their expectations were met and how the modules impacted their students' learning. A similar set of survey items were also administered to the students to elicit their perceptions about the module and how it impacted their motivation and learning. The quantitative data obtained from the surveys were triangulated with other qualitative data gathered from (i) the open-ended questions in the teachers' post-survey; (ii) focus group interviews with the students as well as (iii) observations that were made of the consultation process between the scientists, teachers and technology partner during the E $\Delta$ RTH e-module development; the teachers' professional development by the scientists and educational technologists that prepared the teachers to implement the e-module; and the classroom activities during the implementation of the e-module. Field notes from these observations were kept and drawn on where appropriate to address the research question.

\section{Sampling}

A total of 260 Year 10 students and 19 teachers across three schools in New South Wales, Australia, participated in the E $\triangle$ RTH project. All three schools were single-sexed schools with two of the schools being government girls' schools and the third school a non-government boys' school.

\section{Data Collection and Analysis}

The data collection and analysis methods aligned closely with that reported by Ng and Fergusson (2017). In the initial consultation phase, the teachers were given the opportunity to provide input into the design of the modules. They took part in focus group interviews where their views on effective practice in the use of digital technology in science teaching were elicited to help the technology experts design the e-module. The qualitative data collected consisted of transcriptions of audio-recorded teachers' focus group interviews at the pre-project stage as well as students' post-project interviews. Extensive researcher field notes were taken throughout the project during teacher workshops, classroom observations and informal conversations held with teachers during visits to schools. The field notes provided an audit trail of decisions made about the direction of the research. Qualitative data were analysed for themes that emerged from interview transcripts and open-ended question responses. The rigor of the qualitative data was ensured using Guba and Lincoln's (1986) criteria of trustworthiness, as described above.

Quantitative data collected from the post-project online surveys for teachers and students consisted of a set of Likert-style statements that used a four-point scale (strongly agree, agree, disagree, strongly disagree) and openended questions. Six of the items on learning and interactions with the E $\Delta$ RTH module were the same on both student and teacher's survey in order to investigate how well their perceptions matched. The students' survey consisted of additional items on whether they were in control of their own learning, if they would like their teachers to be more involved and whether this type of learning (with technology) is better than the way they normally learnt science in the classroom. Two items asking about the influence of the module on their uptake of science subjects in Year 11 and their choice of science as a career were also included. The teachers' survey had an additional four items relating to the design of the module e.g. the visual appeal, the graphics and the navigation. The items in the survey were validated by teachers. The SPSS statistical package was used to analyse the means and standard deviations (SD) of the items in the questionnaire. Cronbach alpha was obtained using SPSS to test the reliability of the quantitative responses. A Cronbach alpha value of greater than .6 is acceptable as showing internal consistency. Mean values greater than 2 for the items are considered positive.

An open-ended question in the students' survey asked for general comments and how their learning experience could be improved. The open-ended questions in the teachers' survey asked about the most effective and least effective aspects of the e-module as well as its impact on their students' learning, the use of the analytics captured on the platform and how the e-module could be improved. 


\section{RESULTS AND DISCUSSION}

\section{Teachers' Input into the Climate Change E-module}

At the consultation stage, the Y10 teachers externalised their pedagogical knowledge to assist with the design of the E $\triangle \mathrm{RTH}$ module. The emergent expectations that were revealed in the teachers' pre-project focus group interviews are:

- Technical. The teachers indicated that the educational designers and software developers should consider the technical accessibility to the module such as students' being able to use their schools' email and password to login rather than to have to remember another set of username and password for the module. They should also consider the different platforms for schools in light of the bring-your-own-device (BYOD) phenomenon in schools as well as the schools' network system to ensure that it can cater for several classes to $\log$ in and access the e-module at the same time. Examples of comments are:

Consider the different devices and platforms that students will be using now that laptops are no longer supplied (Teacher 6)

Hardware issues - network, laptops, speed, battery (Teacher 8)

- Motivating and engaging. All the teachers interviewed indicated that the learning resource should be something different and not just out of a textbook.

- Interactive and less text. As students generally do not like to read a lot of text, and the multicultural nature of most of the classes where there are a number of students with English as a second language background, the teachers suggested interactivity and the visual aspects of the learning such as incorporating videos as being crucial to motivating and engaging the students. Talking heads in videos were welcomed but the talking should also be reduced to a minimum. Examples of comments are:

There has to be some sort of value or meaning to what they' re doing. So if you just put them on there to watch a tutorial they'll just click through it as quickly as they can. But if there's some sort of reward or some sort of task or interactive game or something with that then kids get more value out of it (teacher 10).

They can watch the video... they really do enjoy it, the interactive nature of it, the audiovisual side of it is motivating (Teacher 2)

- Game-like. Teachers perceived that students were attracted to and easily absorbed in games and could spend hours on games. Hence it would be motivating and engaging for the students if the module was interactive, inquiry-based and game-like that have levels of challenges that would motivate the students to move on to the next level. Examples of comments are:

Students seem to be able to focus on games for hours so need to tap into that interest in games for their learning...just in a game format (teacher 6)

Gamifying isn't just about putting something on a computer, it's about really clear strategies about how to lead people on to keep doing stuff and that is what good games do. They have an addictive quality. Need to tap into addictive quality of games (Teacher 12)

- Promote scientific literacy and skills development. The teachers expressed an expectation that they wanted more skills-based material in the module than just content-focused materials as indicated in the comments below:

I was kind of hoping that if wouldn't be so much read this, next, read this, next...because in my experience kids, if there is a next button they will just press it no matter what until they get to the end and if there is some sort of question at the end, multiple choice that they have to complete they will just try every answer until it goes through (Teacher 2).

Anything that makes them more scientifically literate is an outcome in itself that is not directly quantifiable. Just by kids being more interested and going onto Year 11 and 12 science (Teacher 5). 
- Personalised learning and feedback. The teachers indicated that if there was feedback from the system on their individual attempts in the e-module, it would help the students learn better in a non-threatening way.

I also have an expectation....like bringing in that assessment for learning business that we are meant to be incorporating more into our teaching and learning. So they achieve something, yes, now I know I can move onto the next level or I need to know more about that or go and get some help or something, so they are getting that feedback (Teacher 6).

- Assessment data for teachers. The teachers expressed interest in being able to monitor and assess the progress of their students.

...data where we look at how we taught something and whether we taught it effectively and so we are looking at science teaching as a science. This is what interest me most and the expectations that we all have access to that data for each of our clasess as a spit up of how each area that we taught was responded to, so we can find areas for improvement next time (Teacher 5).

\section{Description of the Product: EARTH e-Module}

The e-module E $\triangle \mathrm{RTH}$ that was produced reflected most of the expectations of the teachers. It was an integrated STEM module that promoted climate science literacy. The e-learning asset bridged the gap between physical laboratories and science classes so that students were equally able to access it regardless of geographic isolation or socio-economic status.

To motivate and engage digitally connected students of today, the E $\Delta \mathrm{RTH}$ narrative was futuristic and gamelike with the problem to solve being to find a new planet to colonise and rebuild a new E $\Delta$ RTH and its climate system where people could migrate to and tourists could visit. The students were required to locate a suitable source of energy such as a star that will not ignite the sky or freeze the atmosphere. They were required to create an atmosphere that stabilised the planet at a healthy temperature. As the students successfully build an E $\Delta$ RTHlike planet and as it grew in population, they will be faced with another problem. Changes to the climate was happening where some residents believed that the climate system's delicate balance was threatened by the very people occupying the planet while others believed that the changes were due to nature, and still others who believed that nothing was happening at all. The students were required to gather the evidence, assess the claims, considered what they have learned and to argue their case in order to lead the planet to a solution that will ensure its sustainability and survival. In this respect, they developed skills that were transferable to other science-related discussions and decision making situation such as STEM-cell therapy, in-vitro fertilisation and an automated future - issues that will affect their lives.

E $\Delta$ RTH was designed by scientists from a Climate Change Research Centre at one of the partner universities in the project. The e-module was made up of four units where within each unit, there were several lessons. The content and concepts the students studied addressed the Stage 5 syllabus content of the Australian Curriculum: Science as shown in Table 1. 
Table 1. The Content and Concepts the Students Studied in the EDRTH e-Module

\begin{tabular}{|c|c|}
\hline Stage 5 Australian Curriculum: Science content & ESRTH e-module concepts/activities \\
\hline $\begin{array}{l}\text { Energy transfer through different mediums can be } \\
\text { explained using wave and particle models (ACSSU182) }\end{array}$ & $\begin{array}{l}\text { - Investigating the transfer of heat in terms of convection, conduction } \\
\text { and radiation, and identifying situations in which each occurs. } \\
\text { - Exploring the properties of waves, and situations where energy is } \\
\text { transferred in the form of waves, such as sound and light }\end{array}$ \\
\hline $\begin{array}{l}\text { Energy conservation in a system can be explained by } \\
\text { describing energy transfers and transformations } \\
\text { (ACSSU190) }\end{array}$ & $\begin{array}{l}\text { - Recognising that the Law of Conservation of Energy explains that } \\
\text { total energy is maintained in energy transfer and transformation. } \\
\text { - Using models to describe how energy is transferred and transformed } \\
\text { within systems. }\end{array}$ \\
\hline $\begin{array}{l}\text { Global systems, including the carbon cycle, rely on } \\
\text { interactions involving the biosphere, lithosphere, } \\
\text { hydrosphere and atmosphere (ACSSU189) }\end{array}$ & $\begin{array}{l}\text { - Explaining the causes and effects of the greenhouse effect. } \\
\text { - Investigating how human activity affects global systems }\end{array}$ \\
\hline $\begin{array}{l}\text { People can use scientific knowledge to evaluate } \\
\text { whether they should accept claims, explanations or } \\
\text { predictions (ACSHE160) }\end{array}$ & $\begin{array}{l}\text { - Considering the impacts of human activity on an ecosystem from a } \\
\text { range of different perspectives. } \\
\text { - Using knowledge of science to test claims made in advertising or } \\
\text { expressed in the media } \\
\text { - Considering the scientific knowledge used in discussions relating to } \\
\text { climate change }\end{array}$ \\
\hline $\begin{array}{l}\text { Advances in scientific understanding often rely on } \\
\text { developments in technology and technological } \\
\text { advances are often linked to scientific discoveries } \\
\text { (ACSHE192) }\end{array}$ & $\begin{array}{l}\text { - Considering how computer modelling has improved knowledge and } \\
\text { predictability of phenomena such as climate change and atmospheric } \\
\text { pollution. }\end{array}$ \\
\hline $\begin{array}{l}\text { Plan, select and use appropriate investigation methods, } \\
\text { including field work and laboratory experimentation, to } \\
\text { collect reliable data; assess risk and address ethical } \\
\text { issues associated with these methods (ACSIS199) }\end{array}$ & $\begin{array}{l}\text { - Using modelling and simulations, including using digital technology, } \\
\text { to investigate situations and events } \\
\text { - Using models to explain phenomena and make predictions (WS8e, } \\
\text { ACSIS199b). } \\
\text { - Evaluating different approaches used to solve problems (WS8g; } \\
\text { ACSIS172c) }\end{array}$ \\
\hline
\end{tabular}

The concepts covered promoted climate science literacy by helping students understand scientific knowledge relating to climate change such as greenhouse gases, albedo, heat transfer and energy transformation. The content information in the module was delivered by talking heads as bite-sized dialogues interjected with light humour and popular culture sound bites. As the students interacted with the module, they tested their understanding by responding to multiple choice questions, open-ended text questions, drag and drop as well as graphing exercises. Their responses to attempted questions were captured by the software, including the number of attempts and the time of completion. These analytics are further discussed below.

\section{Simulations}

The interactivity of the E $\triangle \mathrm{RTH}$ e-module included climate model simulations where students were able to run various tests to determine what could have caused the temperature increase. For example, students learnt about the atmosphere and its makeup, focusing on greenhouse gases as well as how the atmosphere would impact on the energy balance and planetary temperature. They were introduced to the Virtual Energy Balance Imager (see Figure 2 screenshot), to study the relationship between incoming and outgoing radiation and how that would impact on the planet's temperature. 


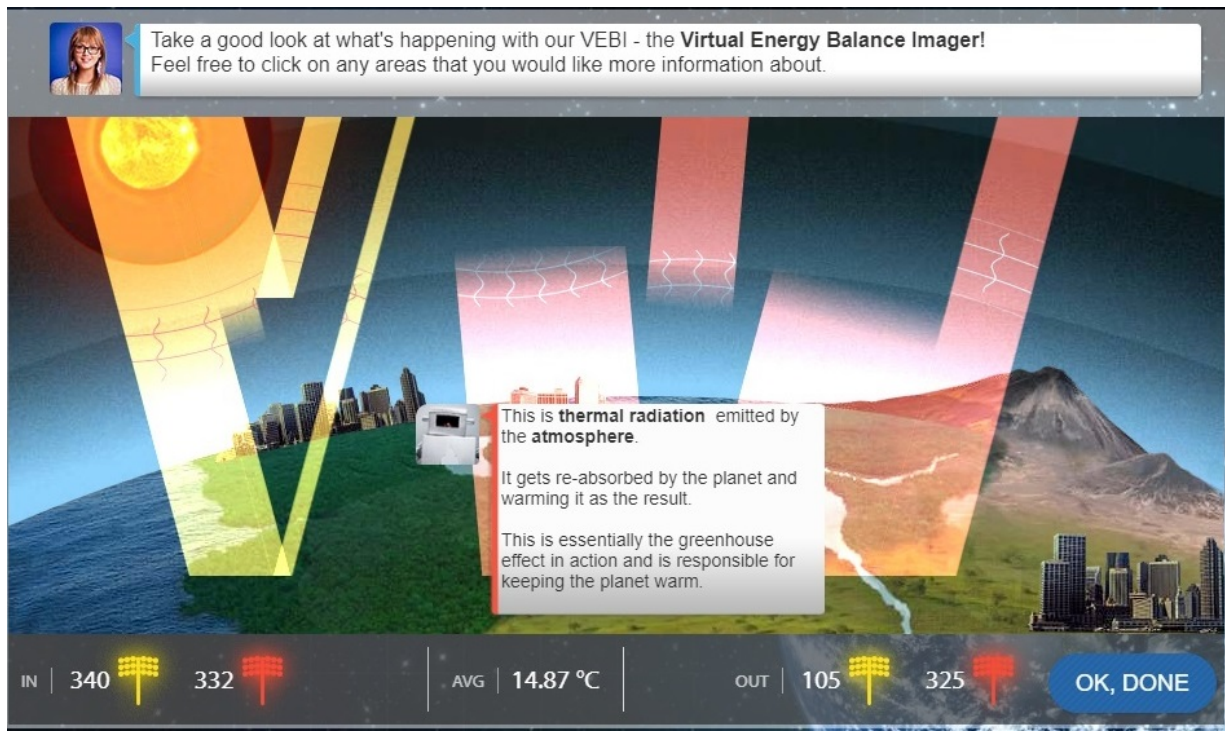

Figure 2. Screenshot of the Virtual Energy Balance Imager

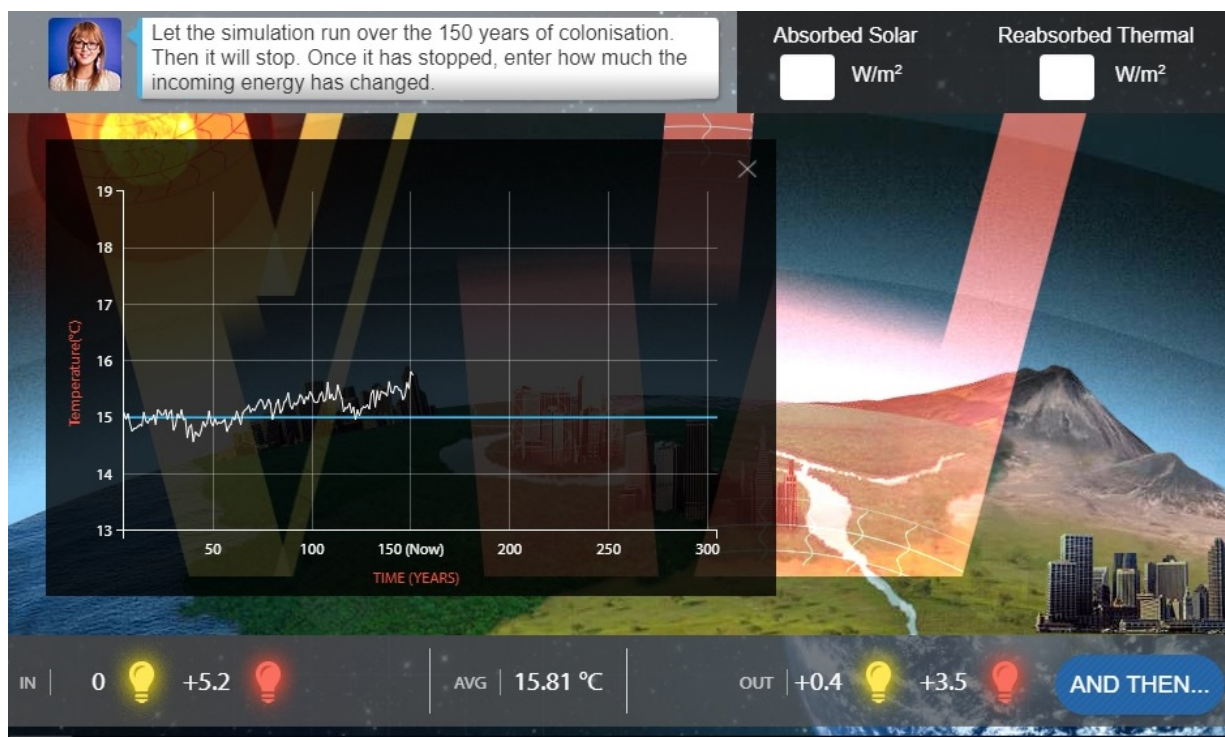

Figure 3. Simulation over 150 years of colonisation and impact on temperature

Figure 3 shows a screenshot of the Virtual Energy Balance Imager that could simulate what happened over 150 years of colonisation of a planet and the impact on the planet's temperature. It looked at everything that's happening, from the activities of the Sun and volcanoes erupting to the impact of gases and pollution from industries. Students were able to run a series of tests to find out what factors caused the rise in temperature and if these were natural or the result of human activities. Other simulations included finding a planet and building the planet. The interactive e-module provided the students with ownership of their planet and an investment in its wellbeing. It demonstrated to students how computer modelling has improved knowledge and predictability of phenomena such as climate change and atmospheric pollution. The scientists and designers' aims were to closely emulate the history and conditions of our earth so that the students could transfer experiences and knowledge obtained from interacting with the E $\triangle \mathrm{RTH}$ e-module to the current issues of climate change.

\section{Analytics}

Monitoring and assessing students' progress and performance is an important role of every teacher. To provide just-in-time support, teachers need to be constantly aware of students' performance in order to intervene appropriately.

The learning platform for E $\triangle \mathrm{RTH}$ was adaptive and had learning analytics capabilities that enabled teachers to analyse their students' learning as well as adjust parameters to cater to the students' needs. Research has shown 


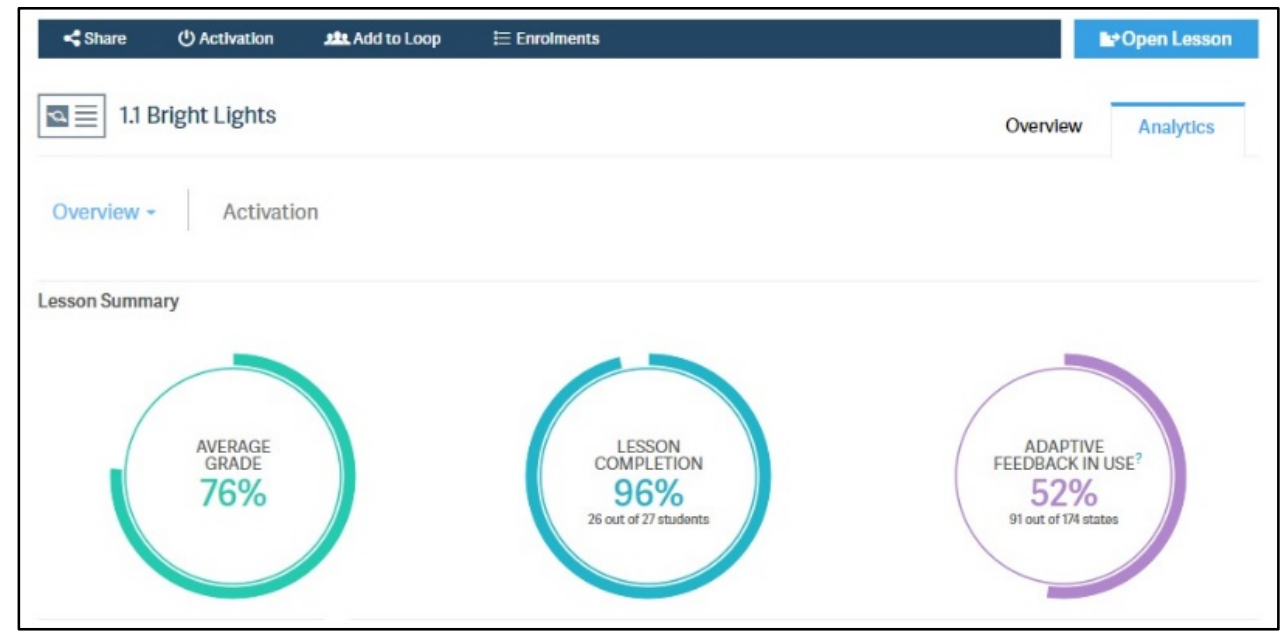

Figure 4. Screenshot of class performance analytics

\begin{tabular}{|c|c|c|c|c|c|c|c|}
\hline Students & 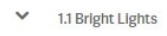 & $\hat{\imath}$ & 1.2 The Goldllocks Zone & $\hat{\imath}$ & 1.3 On the Surface & $\hat{\imath}$ & 2.1 The Blue Planet \\
\hline$\ldots$ & $14 \%$ & & $0 \%$ & & $0 \%$ & & $0 \%$ \\
\hline - & $100 \%$ & & $100 \%$ & & $7 \%$ & & $100 \%$ \\
\hline Ya & $100 \%$ & & $100 \%$ & & $100 \%$ & & $11 \%$ \\
\hline wi & $100 \%$ & & $100 \%$ & & $100 \%$ & & $100 \%$ \\
\hline 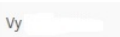 & $100 \%$ & & $100 \%$ & & $100 \%$ & & $100 \%$ \\
\hline " & $100 \%$ & & $100 \%$ & & $100 \%$ & & $100 \%$ \\
\hline . & $100 \%$ & & $100 \%$ & & $100 \%$ & & $100 \%$ \\
\hline . & $100 \%$ & & $100 \%$ & & $100 \%$ & & $100 \%$ \\
\hline 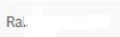 & $100 \%$ & & $100 \%$ & & $100 \%$ & & $100 \%$ \\
\hline Ra & $100 \%$ & & $100 \%$ & & $100 \%$ & & $100 \%$ \\
\hline Ne. & $100 \%$ & & $100 \%$ & & $100 \%$ & & $100 \%$ \\
\hline Na & $100 \%$ & & $63 \%$ & & $0 \%$ & & $100 \%$ \\
\hline \multirow[t]{2}{*}{ ма } & $100 \%$ & & $100 \%$ & & $100 \%$ & & $100 \%$ \\
\hline & 1nnex & & 1nnex & & (1002 & & 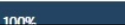 \\
\hline
\end{tabular}

Figure 5. Screenshot of individual performance analytics

that when teachers had access to learning analytics, they were more confident to act and intervene to offer general support to the class as well as to specifically target individuals or groups that demonstrate difficulties in their learning (Van Leeuwen, Janssen, Erkens, \& Brekelmans, 2015). The screenshot in Figure 4 shows the progress of a class' performance for the lesson on Bright Lights where the teacher was able to see the completion rate of the class and average score of the exercises attempted. At an individual level, the screenshot in Figure 5 shows the completion of lessons within a unit by each student in the class. Other analytics information includes solution trace graphs for each question that can be retrieved to indicate to the teacher the number of attempts the students have tried to answer the question correctly. In graphs which indicated that most students were unable to arrive at the correct answer after 4 attempts, it would suggest to the teachers that intervention is required for the concept being tested. In addition, all the responses to open-ended questions that students have input into the system were captured for teachers to analyse. This helps the teacher to identify misconceptions in students, particularly weaker students and how their thinking has evolved. The system's feedback provided timely intervention by the teacher in aiding students' learning.

\section{Implementation of the EARTH E-module}

To help the Year 10 teachers internalise the TPACK aspects of the new EARTH e-module, professional development for the teachers were delivered by the content and technology experts as in-house workshops at each of the participating schools. They were required to re-align their existing TPACK with the new knowledge and skills required to implement the module in their classrooms. At these hands-on workshops, the science teachers 
Table 2. Teachers' perceptions of the impact of the E $\triangle R T H$ module on their students' learning

\begin{tabular}{|c|c|c|}
\hline Teachers $\mathrm{N}=6$; Cronbach alpha $=.786$ & Mean & Std. Deviation \\
\hline \multicolumn{3}{|l|}{ LEARNING } \\
\hline 1. My students learned a lot about science from the E $\Delta$ RTH module. & 2.83 & .41 \\
\hline $\begin{array}{l}\text { 2. My students' understanding of scientific processes and how scientists work has increased as } \\
\text { a result of doing the } E \triangle R T H \text { module. }\end{array}$ & 2.67 & .52 \\
\hline $\begin{array}{l}\text { 3. My students have a better understanding of the life and work of scientists as a result of } \\
\text { doing the } E \triangle R T H \text { module }\end{array}$ & 2.67 & .52 \\
\hline $\begin{array}{l}\text { 4. My students were motivated by the feedback they got from the activities in the E } \Delta \mathrm{RTH} \\
\text { module. }\end{array}$ & 2.83 & .41 \\
\hline 5. My students were challenged to learn by the E $\Delta R T H$ module & 2.67 & .52 \\
\hline 6. The $\mathrm{E} \Delta \mathrm{RTH}$ module promotes collaboration and peer discussion. & 3.17 & .41 \\
\hline \multicolumn{3}{|l|}{ MODULE DESIGN and PRESENTATION } \\
\hline 7. The E $\triangle \mathrm{RTH}$ materials were visually appealing and motivating. & 3.00 & .00 \\
\hline $\begin{array}{l}\text { 8. The choice of text font, colours and style used in the E } \Delta R T H \text { module helped the students to } \\
\text { read and listen clearly, and understand concepts easily. }\end{array}$ & 3.00 & .00 \\
\hline $\begin{array}{l}\text { 9.The graphics (photos, graphs, images) were appropriately designed to help the students } \\
\text { understand the topic }\end{array}$ & 3.17 & .41 \\
\hline 10. The navigation of the E $\Delta R T H$ lessons was well designed and easy to use & 3.00 & .00 \\
\hline
\end{tabular}

worked through one of the lessons in the module with the experts to understand the narrative and the inquiry format of the module, to use the analytics, to conceptualise the connections between the content and science inquiry skills requirements of the Australian Curriculum: Science and to plan pedagogically the implementation of the module in their teaching. Time and effort were required for the teachers to actively internalise the new content knowledge and technology tools in order to facilitate the learning of their students using the e-module.

The classroom observation data indicated that the mode of implementation was mostly stand-alone, that is, students interacted and solved the problems in the e-module on their own rather than as an integrated classroom learning activity. Of the 19 teachers who participated in the use of the e-module in the classrooms, only nine participated in the post-project survey, with six full completion, a 32\% completion rate. The post-project survey responses indicated that $67 \%$ of the teachers implemented the module as a stand-alone activity. In the stand-alone mode of learning, the students obtained help from their peers with some of them directing questions occasionally to their teachers. In some cases the teachers were not able to answer, depending on the level of preparation they made. One of the teachers requested for a teacher's guide, a booklet with answers to the questions in the module.

\section{Science Teachers' Perceptions of the Impact of the Smart Science Modules on Their Students' Learning}

The quantitative results in Table 2 show that the Y10 teacher participants who completed the post-project survey were positive about the E $\triangle \mathrm{RTH}$ e-module, with the mean values larger than 2.5 (out of a maximum of 4) for all the items that sought their perceptions of the impact of the e-module on their students' learning. They were positive about their students having learned a lot about the science on climate change as well as scientific processes and scientists' work from the modules (mean values 2.83, 2.67 and 2.67 respectively).

The teachers were similarly positive about the items that their students were motivated by the feedback provided in the module and were challenged to learn by the module (mean values 2.83 and 2.67 respectively). The item that the e-module promoted collaboration and peer discussion amongst the students scored the strongest agreement with mean value of 3.17 .

With respect to the design of the presentation of the content in the e-module, the post-project survey also indicated that there was $100 \%$ agreement that the online materials were motivating, visually appealing and that the navigation of the lessons were well designed and easy to use (mean value $=3.00, \mathrm{SD}=0.00$ ) for all three items. There was stronger agreement for the item on the use of fonts, colours, style and graphics to help their students read and listen clearer to better learn the concepts (mean value $=3.17 \pm 0.41$ ).

The open-ended (qualitative) responses of the teachers supported the positive quantitative responses in Table 2. The teachers listed the most effective features of the E $\triangle \mathrm{RTH}$ module as: the very interactive nature of the module, a lot of content was covered, visually appealing and allowed students to work at their own pace. Examples of quotes from the teachers are: 
For the more academically inclined students it was challenging and interesting. They enjoyed taking control of their learning and some students did log on at home to complete lessons. They understood the concept and enjoyed working on their planet. It was also beneficial to be able to track the students. (Teacher 6)

With respect to the least effective features, the teachers indicated: the light-humour/popular culture text dialogues were not effective, technical difficulties and glitches in some areas, some of the content were too difficult and needed more hints/help and too much reading for some of their students. Examples of quotes from the teachers are:

The dialogue would have been more effective if it was audio or animated students of lower abilities/focus capabilities would have engaged in the context of the module. (Teacher 4)

The difficult questions, that they were unable to progress beyond without help. Maybe some hints could be built into the program to overcome this problem. The other huge drawback was the technical difficulties that we experienced - we wasted a lot of class time because of this. (Teacher 5)

Too much reading for the students with poorer reading skills. The level was set quite high and did not cater well for these students. Perhaps an audio of the conversation between characters and instructions would have been helpful for these students. (Teacher 6).

Half of the teachers who completed the survey and open-ended qualitative questions indicated that they started using the analytics but did not find the time to use more. They and the other teachers who did not make use of the analytics were tied up with helping students in the classroom rather than referring to the analytics. None indicated looking at the data outside of class time.

The recommendations the teachers made for improvement were: shorten some of the activities so that they are less repetitive, less content/theory, clearer instructions/more hints in some areas to help students to progress, better jokes and technical issues such as glitches that cause the screen to freeze need to be tidied up. Examples of quotes to support this are:

Needs to be less repetitive. Tasks such as the plotting of stars needn't take so long. Students also found it frustrating that when they got an answer wrong, they had to keep trying until a right answer was achieved. While I think this is great, students who aren't motivated will give up. (Teacher 1)

Some of the interactive conversations were a little bit lame. (Teacher 3)

The difficult questions need to be made more accessible. Possibly they could be streamlined, so that there is not as much theory to wade through before getting to the more enjoyable part of the module and I think some of the questions went beyond what the students needed to know. If it was a bit shorter and easier, it would have been more gratifying - as it is, it was a bit boring and they found it tedious when they kept getting stumped by the questions (those who could answer them enjoyed it much more). (Teacher 4).

\section{Y10 Students' Perceptions of the Impact of the Smart Science Modules on Their Learning}

Two hundred and sixty students participated in the online survey that asked six similar questions to those in the teachers' survey. This is to examine how well the perceptions of the students matched those of the teachers who participated in the survey by looking at the positiveness of the perceptions for each item.

The students' quantitative data in Table 3 shows similar positive perceptions to the six items as their teachers'. 
Table 3. Students' perceptions of the impact of the $E \Delta R T H$ module on their own learning

\begin{tabular}{|c|c|c|}
\hline Cronbach alpha $=.93 ; \mathrm{N}=259$ & Mean & Std. Deviation \\
\hline \multicolumn{3}{|l|}{ LEARNING } \\
\hline 1. I learned a lot about science from the $\mathrm{E} \Delta \mathrm{RTH}$ module. & 2.52 & 0.80 \\
\hline $\begin{array}{l}\text { 2. I believe that my understanding of scientific processes and how scientists work has increased } \\
\text { as a result of doing theE } \Delta R T H \text { module. }\end{array}$ & 2.56 & 0.81 \\
\hline $\begin{array}{l}\text { 3. I have a better understanding of the life and work of scientists as a result of doing the E } \triangle R T H \\
\text { module. }\end{array}$ & 2.56 & 0.81 \\
\hline 4. I was motivated by the feedback I got from the activities in the E $\Delta R T H$ module. & 2.73 & 0.79 \\
\hline 5. I was challenged to learn by the $\mathrm{E} \Delta \mathrm{RTH}$ module. & 2.51 & 0.88 \\
\hline 6. The E $\triangle \mathrm{RTH}$ module promotes collaboration and peer discussion. & 2.77 & 0.85 \\
\hline 7. I would like the teacher to be more involved in my learning with the E $\Delta$ RTH lessons. & 2.60 & 0.84 \\
\hline 8. I felt that I was in control of my learning when doing the $E \Delta R T H$ module. & 2.49 & 0.85 \\
\hline $\begin{array}{l}\text { 9. Learning science using the } E \Delta R T H \text { module was better than the way we normally learn } \\
\text { science. }\end{array}$ & 2.82 & 0.81 \\
\hline 10. I was motivated and sufficiently independent to learn well by doing the E $\Delta R T H$ module. & 2.63 & 0.79 \\
\hline \multicolumn{3}{|l|}{ FUTURE INVOLVEMENT IN SCIENCE } \\
\hline 11. I am more likely to take a science subject in Year 11 as a result of doing the E $\Delta$ RTH module. & 3.30 & 0.73 \\
\hline 12. The $E \Delta R T H$ module has influenced me to choose a career in science. & 3.28 & 0.69 \\
\hline
\end{tabular}

The items 1-6 in Table 3 all scored mean values of over 2.5 (out of a maximum of 4). Even though the majority of the students would like their teachers to be more involved in their learning with the e-module (mean value=2.6), they were still quite positive about being in control of their own learning (mean=2.49) as well as motivated and sufficiently independent to learn well (mean=2.63). The students were also positive about learning science this way (mean=2.82). For item 6 'the E $\triangle$ RTH module promotes collaboration and peer discussion', the mean value is 2.77 which is positive although somewhat lower than the mean value obtained from the teacher (mean $=3.17$ ).

For the items (11 and 12) that surveyed the students' future involvement in science, the Year 10 students indicated strong agreement about doing a science subject in Year 11 and choosing a career in science as a result of having undertaken the EARTH module (mean values of 3.30 and 3.28 respectively).

The open-ended qualitative responses from the question that asked for the students' comments and suggestions for improvement were somewhat mixed. Of the 260 student participants, there were only 59 responses, representing only $23 \%$ of participants responding. The negative responses appeared to outweigh the positive in approximately a ratio of 3:2. This does not match with the generally positive responses from the quantitative section of the survey. A possible explanation is that since the majority of the students (77\%) did not respond to the openended question, those who sought to respond were likely to be the students who had unsatisfactory experiences. Analysis of the open-ended responses shows that there were three major issues (i) technical issues (ii) the e-module content was too difficult hence became boring and uninteresting for the more negative students and (iii) the sense of humour did not appeal to these students and annoyed them instead. Examples of quotes to support this are:

It was a real shame about all the bugs that happened during the module, because otherwise it could've been a quite decent module (issue 1)

It was hard to learn, as there were many glitches (issue 1)

It was too in-depth and tedious. An improvement for this would be more concise and summarised topics condensed into a smaller number of modules, so that the process of finishing te activity isn't as laborious. (issue 2)

For people not heavily interested in science, there are many terms that are said that people wouldn't understand (issue 2)

I think that a the only major issue i has with the unit was that in the event of getting an answer wrong, instead of allowing you to come to an answer with the appropriate 'clues' or information we have to keep on trying the various combinations until it was accepted (issue 2)

Maybe take out the unuseful and irrelevant conversation between the characters - it just makes the process laggy and less enjoyable (issue 3)

The humour was quite dry but the overall experience was good nonetheless (issue 3) 


\section{CONCLUSIONS AND IMPLICATIONS}

The research investigated the impact of a school-university-industry partnership-designed technology-based online module on climate change for the teaching and learning of Y10 students. The results indicate that engaging teachers in the design of the e-module that they will use in their classroom produced positive attitudes towards the use of the materials with their students. The engagement of teachers as partners ensured that the curriculum requirements were met, further motivating teachers to make use of the e-module. Their expectations however were not all met because how they viewed a game was somewhat different from how the scientists and technology partner viewed it. The teachers viewed 'game' as a program that has in-built competition where rewards are given for answering questions correctly and where there are different levels of challenges. Scientists and the technology partner, however, saw 'games' as the challenge to solve the problem at hand and to use the system's feedback to solve it. Similarly, how students viewed humour was different from how the scientists/technology partner viewed it. In addition, the content-laden and text-based aspects of some areas of the e-module meant that the weaker students, and students from a non-English speaking background were not able to grasp all of the content. There was a 'generation gap' as well as lack of understanding in differentiation in these respects and it would have been better if the Y10 students were consulted as well at the scripting stage prior to final production. An implication for teachers would be that there need to be more scaffolding for these students. There could be professional development workshops conducted by the experts on how this could be achieved or an online community (e.g. through a blog) of teachers using the E $\Delta$ RTH module could be created where the teachers could share ideas on how this could be achieved. Successful teachers in the research were those who invested time to explore the e-module to internalise and re-align their TPACK.

Students' prior knowledge and misconceptions were gathered as part of this project but it is beyond the scope of this paper to report on them. In general, however, most of the teachers found that their students learnt a lot about climate science and had better understanding of the scientific processes and the work of scientists. Students studying with designed materials such as the E $\triangle$ RTH materials can be certain of the accuracy of the information presented and learn confidently about climate science. This should prepare them to be better equipped with reasoning and debating about climate change and its impact on the earth and society.

\section{LIMITATIONS AND FUTURE STUDIES}

A limitation of the study is the low number of teachers who completed the survey, due possibly to the timing of the survey which was released towards the end of the year, during a period of intense activities in schools. Hence the results are not generalisable and need to be viewed with caution. The types of schools involved (only single-sex schools) in the research and the gathering of data from one state only in Australia contribute to the limitation of the study.

Future research should include measuring the performance of the students using the e-module in terms of knowledge gained on climate science as well as the ability to apply the concepts in debating about or solving problems associated with climate change and the environment. Research should be conducted on trials of the emodule in different types of schools such as single-sex versus co-educational schools, independent versus government schools, metropolitan versus rural/remote schools and schools with students from different socioeconomic backgrounds. While the use of the e-module was largely independent study by the students in this research, teachers should look at an integrated (blended) approach that include scaffolding and differentiation and the students' performance outcomes measured.

\section{ACKNOWLEDGEMENTS}

The author wishes to acknowledge the Australian Maths and Science Partnership Program funding as well as the Smart Science Initiative team from the Climate Change Research Centre at the University of New South Wales and the Smart Sparrow team for the development of the EARTH e-module. Thank you also to Dr Khar Thoe Ng from SEAMEO-RECSAM for her contribution to this paper.

\section{REFERENCES}

Boyes, E., \& Stanisstreet, M. (1998). High school students' perceptions of how major global environmental effects might cause skin cancer. The Journal of Environmental Education, 29(2), 31-36. https:/ / doi.org/10.1080/00958969809599110

Dawson, V. (2012). Science teachers' perspectives about climate change. Teaching Science, 58(3).

Dawson, V., \& Carson, K. (2013). Australian secondary school students' understanding of climate change. Teaching Science, 59(3), 9-14. 
Dupigny-Giroux, L. A. L. (2010). Exploring the challenges of climate science literacy: Lessons from students, teachers and lifelong learners. Geography Compass, 4(9), 1203-1217. https://doi.org/10.1111/j.17498198.2010.00368.x

Guba, E. G. (1981). ERIC/ECTJ annual review paper: criteria for assessing the trustworthiness of naturalistic inquiries. Educational Communication and Technology, 29(2), 75-91.

Guba, E. G., \& Lincoln, Y. S. (1994). Competing paradigms in qualitative research. Handbook of qualitative research, 2(163-194), 105.

Heimlich, J., \& Ardoin, N. (2008). Understanding behavior to understand behavior change: A literature review. Environmental Education Research, 14(3), 215-237. https:/ / doi.org/10.1080/13504620802148881

Hewson, P. W., A'B, H. \& Mariana, G. (1988). An appropriate conception of teaching science: A view from studies of science learning. Science Education, 72(5), 597-614. https:/ / doi.org/10.1002/sce.3730720506

Hill, J. L., \& Nelson, A. (2011). New technology, new pedagogy? Employing video podcasts in learning and teaching about exotic ecosystems. Environmental Education Research, 17(3), 393-408. https://doi.org/10.1080/13504622.2010.545873

Huertas, A., \& Adler, D. (2012). Is News Corp. failing science? Cambridge, MA: Union of Concerned Scientists.

Jimoyiannis, A. (2010). Designing and implementing an integrated technological pedagogical science knowledge framework for science teachers' professional development. Computers E Education, 55(3), 1259-1269. https://doi.org/10.1016/j.compedu.2010.05.022

Johnson, I. (2016), Climate change may be escalating so fast it could be 'game over', scientists warn. UK: Independent news online. Retrieved on March 8, 2018 from http:/ / www.independent.co.uk/news/science /climate-change-game-over-global-warming-climate-sensitivity-seven-degrees-a7407881.html

Kamarainen, A. M., Metcalf, S., Grotzer, T., Browne, A., Mazzuca, D., Tutwiler, M. S., \& Dede, C. (2013). EcoMOBILE: Integrating augmented reality and probeware with environmental education field trips. Computers E Education, 68, 545-556. https:/ / doi.org/10.1016/j.compedu.2013.02.018

Leppisaari, I., \& Lee, O. (2012). Modelling digital natives' international collaboration: Finnish-Korean experiences of environmental education. Journal of Educational Technology E Society, 15(2), 244.

Lincoln, Y. S., \& Guba, E. G. (1985). Naturalistic inquiry (Vol. 75): Sage.

Lincoln, Y. S., \& Guba, E. G. (1986). But is it rigorous? Trustworthiness and authenticity in naturalistic evaluation. New Directions for Program Evaluation, 1986(30), 73-84. https:/ / doi.org/10.1002/ev.1427

Manolas, E., \& Leal Filho, W. (2011). The use of cooperative learning in dispelling student misconceptions on climate change. Journal of Baltic Science Education, 10(3), 168-182.

McCaffrey, M. S., \& Buhr, S. M. (2008). Clarifying climate confusion: Addressing systemic holes, cognitive gaps, and misconceptions through climate literacy. Physical Geography, 29(6), 512-528. https:/ / doi.org/10.2747/0272-3646.29.6.512

Mishra, P. \& Koehler, M. (2006). Technological pedagogical content knowledge: a framework for teacher knowledge. The Teachers College Record, 108(6), 1017-1054. https:/ / doi.org/10.1111/j.1467-9620.2006.00684.x

Ng, K. T., Parahakaran, S., \& Thien, L. M. (2015). Enhancing sustainable awareness through SSYS congress: Challenges and opportunities of e-platforms to promote values-based education. International Journal of Educational Science and Research, 5(2), 79-90

Ng, W., \& Fergusson, J. (2015). Evaluation of the Smart Science Initiative project. Retrieved on March 3, 2013 from http://www.smartscience.com.au/evaluation/

Ng, W., \& Fergusson, J. (2017). Technology-Enhanced Science Partnership Initiative: Impact on Secondary Science Teachers. Research in Science Education. https:/ / doi.org/10.1007/s11165-017-9619-1

Oreskes, N. (2004). The scientific consensus on climate change. Science, 306(5702), 1686-1686. https://doi.org/10.1126/science.1103618

Österlind, K. (2005). Concept formation in environmental education: 14-year olds' work on the intensified greenhouse effect and the depletion of the ozone layer. International Journal of Science Education, 27, 891-908. https:/ / doi.org/10.1080/09500690500038264

Papadimitriou, V. (2004). Prospective primary teachers' understanding of climate change, greenhouse effect, and ozone layer depletion. Journal of Science Education and Technology, 13, $299-307$. https:/ / doi.org/10.1023/B:JOST.0000031268.72848.6d

Pruneau, D., Langis, J., Richard, J. F., Albert, G. \& Cormier, M. (2005). The evolution of children's ideas on pollution in the framework of experiential and socioconstructivist activities. Environment and Sustainable Development, 4(1), 17-34. https:/ / doi.org/10.1504/IJESD.2005.006771 
Pruneau, D., Khattabi, A., \& Demers, M. (2010). Challenges and Possibilities in Climate Change Education. USChina Education Review, 7(9), 15-24.

Read, D., Bostrom, A., Morgan, M. G., Fischhoff, B., \& Smuts, T. (1994). What do people know about global climate change? 2 Survey studies of educated laypeople. Risk Analysis, 14, 971-982. https:/ / doi.org/10.1111/j.15396924.1994.tb00066.x

Shulman, L. S. (1987). Knowledge and teaching: foundations of the new reform. Harvard Educational Review, 57(1), 1-23. https:/ / doi.org/10.17763/haer.57.1.j463w79r56455411

US Global change Research Program (2009). Climate Literacy: The Essential Principles of Climate Science. Retrieved on March 12, 2018 from https:/ / downloads.globalchange.gov/Literacy/climate_literacy_highres_english.pdf

Yang, J. C., Chien, K. H., \& Liu, T. C. (2012). A digital game-based learning system for energy education: An energy conservation pet. The Turkish Online Journal of Educational Technology, 11(2).

\section{http://www.ejmste.com}

